\title{
Tachycardia-dependent versus bradycardia-dependent intermittent bundle-branch block
}

\author{
Nabil El-Sherif \\ From the Cardiology Department, Faculty of Medicine, Cairo University, Egypt, U.A.R.
}

Analysis of 16 cases with intermittent bundle-branch block showing rate-dependence revealed the presence of 12 instances with tachycardia-dependent bundle-branch block, 3 with bradycardiadependent bundle-branch block, and one instance showing both types at two different occasions. Tachycardia-dependent bundle-branch block was explained on the basis of cycle length-recovery time relation and revealed a critical rate for normal intraventricular conduction. However, some overlap in the $R R$ cycles of normal and aberrant beats in the same record was frequently seen, especially in the presence of atrial fibrillation. This was attributed to the sensitivity of the action potential duration of the diseased bundle to the possible cumulative effects of cycle length changes. On the other hand, the demonstration of bundle-branch block at widely varying heart rates in records taken on different occasions probably reflects the influence of slowly acting parameters. Bradycardia-dependent bundle-branch block was diagnosed whenever bundle-branch block appeared on slowing of the heart rate or disappeared on its acceleration, and was best explained on the basis of enhanced phase-4 depolarization of the bundle-branch system. The occasional demonstration of a paradoxical relation to cycle length changes under the influence of certain physiological manoeuvres and/or pharmacological agents was explained by the role of these agents in enhancing or depressing phase-4 depolarization.

Transient and intermittent conduction disturbances are more familiar at the atrioventricular (AV) junctional tissue as compared - with the intraventricular conduction system. Though study of the electrophysiological characteristics of the conduction system at the two sites may reveal some variations, yet these are not at all sufficient to explain the observed difference in the relative incidence of the two conditions. The consideration of at least two factors may be helpful in this concern. Firstly, autonomic control may be operating in a good percentage of transient and intermittent AV blocks (though some of the organic affections of the region may be totally reversible). On the other hand, the presence or otherwise of autonomic control on impulse conduction in the bundle-branch

- system and its possible role is still controversial. Secondly, some of the disturbances of impulse conduction at the bundle-branch system may be either difficult to recognize from conventional cardiographic records or may be partially or totally obscured by conRexeived 17 March 197 I. comitant disturbances at the $\mathrm{AV}$ conduction system.

Transient bundle-branch block is usually defined as an intraventricular conduction defect that subsequently returns, if only temporarily, to normal conduction, while intermittent bundle-branch block on the other hand is characterized in the same cardiographic record of complexes showing bundlebranch block and normally conducted beats (Bauer, 1964). However, since some cases of bundle-branch block may prove to be rate dependent (not considering for the moment other intricate factors) and since in many of these cases no attempt is usually taken to uncover probable instances of normal intraventricular conduction (e.g. by inducing a sufficient degree of bradycardia), it will be hard sometimes to make a clear-cut distinction not only between transient and intermittent bundle-branch block but even between permanent and transient blocks. In fact, many cases of intermittent block are usually diagnosed from fortuitously obtained cardiographic records and are rarely actively 
TABLE Pertinent data of (I6) cases of intermittent bundle-branch block

\begin{tabular}{|c|c|c|c|c|c|}
\hline $\begin{array}{l}\text { Case } \\
\text { No. }\end{array}$ & $\begin{array}{l}\text { Age }(y r) \\
\text { and sex }\end{array}$ & Diagnosis & $\begin{array}{l}\text { Conduction } \\
\text { defect }^{\star}\end{array}$ & Rhythm & $\begin{array}{l}\text { Electrocardiogram showing normal } \\
\text { conduction }\end{array}$ \\
\hline $\mathbf{I}$ & $55 \mathrm{~F}$ & $\begin{array}{l}\text { Rheumatic mitral stenosis } \\
\text { and insufficiency }\end{array}$ & LBBB & $\begin{array}{l}\text { Atrial fibrillation; ventricular } \\
\text { ectopic systoles }\end{array}$ & Left ventricular ischaemic pattern \\
\hline 2 & $55 \mathrm{~F}$ & Diabetes & $\begin{array}{l}\text { Left anterior } \\
\text { hemiblock }\end{array}$ & $\begin{array}{l}\text { Sinus; supraventricular ectopic } \\
\text { systoles and tachycardia }\end{array}$ & Normal \\
\hline 3 & $49 \mathrm{~F}$ & $\begin{array}{l}\text { Recent infarction; hyper- } \\
\text { tension; diabetes }\end{array}$ & LBBB & Sinus & Extensive anterior injury pattern \\
\hline 4 & I9 F & Ostium secondum defect & RBBB & Sinus & $\begin{array}{l}\text { Right ventricular hypertrophy of rsR' } \\
\text { pattern }\end{array}$ \\
\hline 5 & $55 \mathrm{~F}$ & $\begin{array}{l}\text { Hypertensive coronary } \\
\text { heart disease }\end{array}$ & LBBB & Sinus & $\begin{array}{l}\text { Left ventricular ischaemic pattern; } \\
\text { ? old anteroseptal infarction }\end{array}$ \\
\hline 6 & $26 M$ & $\begin{array}{l}\text { Ventricular septal defect; } \\
\text { subacute bacterial endo- } \\
\text { carditis }\end{array}$ & LBBB & $\begin{array}{l}\text { Sinus; supraventricular ectopic } \\
\text { systoles }\end{array}$ & Left ventricular ischaemic pattern \\
\hline 7 & $48 \mathrm{~F}$ & $\begin{array}{l}\text { Rheumatic mitral insuffici- } \\
\text { ency }\end{array}$ & LBBB & Atrial fibrillation & $\begin{array}{l}\text { Left ventricular hypertrophy and } \\
\text { ischaemic pattern }\end{array}$ \\
\hline 8 & $58 \mathrm{M}$ & Hypertensive heart disease & LBBB & Atrial fibrillation & Left ventricular ischaemic pattern \\
\hline 9 & 6r M & $\begin{array}{l}\text { Hypertensive coronary } \\
\text { heart disease }\end{array}$ & LBBB & Sinus; ventricular ectopic systoles & $\begin{array}{l}\text { Left ventricular ischaemic pattern; } \\
\text { old inferior infarction }\end{array}$ \\
\hline ro & $65 \mathrm{~F}$ & Recent infarction, diabetes & LBBB & Sinus; ventricular ectopic systoles & Recent extensive anterior infarction \\
\hline II & $53 \mathrm{M}$ & $\begin{array}{l}\text { Hypoxic cor pulmonale, } \\
\text { hypertension }\end{array}$ & RBBB & Sinus; ventricular ectopic systoles & Biventricular hypertrophy \\
\hline 12 & $57 \mathrm{~F}$ & Diabetes & RBBB & Sinus; ventricular ectopic systoles & Normal \\
\hline 13 & $45 \mathrm{~F}$ & $\begin{array}{l}\text { Massive pulmonary } \\
\text { embolism }\end{array}$ & RBBB & $\begin{array}{l}\text { Sinus arrhythmia; supraventricu- } \\
\text { lar ectopic systoles }\end{array}$ & Normal \\
\hline 14 & $52 \mathrm{M}$ & Coronary heart disease & LBBB & Sinus & $\begin{array}{l}\text { Incomplete LBBB; ? septal } \\
\text { infarction }\end{array}$ \\
\hline $\begin{array}{l}15 \\
16\end{array}$ & $\begin{array}{l}49 M \\
55 M\end{array}$ & $\begin{array}{l}\text { Recent infarction } \\
\text { Recent infarction }\end{array}$ & $\begin{array}{l}\text { LBBB } \\
\text { RBBB }\end{array}$ & $\begin{array}{l}\text { Sinus } \\
\text { (1) Sinus + ventricular, ectopic } \\
\text { systoles } \\
\text { (2) Sinus }\end{array}$ & $\begin{array}{l}\text { Acute anterior injury pattern } \\
\text { Anterolateral injury pattern }\end{array}$ \\
\hline
\end{tabular}

* Left or right bundle-branch block.

† Obtained two weeks after the first record.

searched for. The situation is further complicated by the fact that records showing normal intraventricular conduction at a 'reasonable' heart rate may be masking a latent degree of bundle-branch block which would only be uncovered by slight acceleration of the rate or other appropriate measures.

Though many reports on both transient and intermittent bundle-branch block have been published and various studies have been conducted to elucidate the various factors controlling impulse conduction in the bundlebranch system, yet much controversy and a good deal of misconception still prevail. The following review represents a critical discussion of the subject through the study of 16 cases of intermittent bundle-branch block observed in the past 5 years (from January 1965 to December 1969) at Kasr El-Aini Faculty of Medicine of the Cairo University.

\section{Subjects and methods}

Sixteen cases showing rate-dependent intermittent bundle-branch block were analysed. These include I2 cases with tachycardia-dependent block, 3 cases with bradycardia-dependent block, and I case showing both at different occasions (Table). In Io cases multiple records were usually analysed and the cases were followed for variable durations up to 5 years. In these cases, the role of certain physiological manoeuvres and/or pharmacological agents were repeatedly studied. The remaining 6 cases (Cases 7 to 12) were found during a critical review of 50 consecutive cases of bundle-branch block. In these cases, there were one or more records available for analysis but an effective follow-up was usually lacking. In these 50, ectopic systoles were present in 14 and atrial fibrillation in another 6. In 4 records showing ectopic systoles and in 2 others with atrial fibrillation, evidence of normal intraventricular conduction was seen in the beats following the compensatory pauses of the ectopic systoles or the long RR intervals in atrial fibrillation. On the other hand, no single evidence of normal intraventricular conduction was seen in the 30 records showing regular sinus rhythm. This limited statistical survey stresses not only the high incidence of intermittent bundle-branch block but more essentially the value of long RR cycles in revealing probable instances of tachycardia-dependent block. In the presence of ectopic systoles or atrial fibrillation, fortuitously long $\mathbf{R}$ intervals are usually seen. In their absence, however, other bradycardia measures, like caro- 


\author{
Carotid sinus compression, amyl nitrite; exercise; atropine, adenosine \\ triphosphate
}

-

Amyl nitrite

Exercise; atropine

Carotid sinus compression

Carotid sinus compression

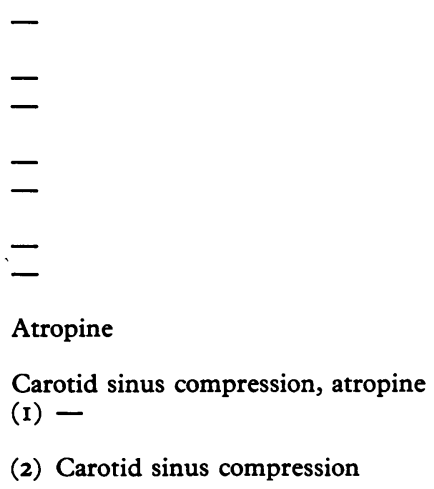

Tachycardia-dependent

Tachycardia-dependent

Tachycardia-dependent

Tachycardia-dependent

Tachycardia-dependent

Tachycardia-dependent

Tachycardia-dependent

Tachycardia-dependent

Tachycardia-dependent

Tachycardia-dependent

Tachycardia-dependent

Tachycardia-dependent Bradycardia-dependent

Bradycardia-dependent

Bradycardia-dependent

(I) Tachycardia-dependent

(2) Bradycardia-dependent $†$ tid sinus compression, should be consistently used.

Pertinent data of all the cases are summarized in the Table, while illustrative examples of each group will be critically analysed.

\section{Tachycardia-dependent bundle-branch block}

Case I A 55-year-old woman with rheumatic mitral stenosis and incompetence was first admitted to hospital in January 1965. Her cardiographic record revealed atrial fibrillation and intermittent left bundle-branch block (Fig. I). The beats with normal intraventricular conduction showed left ventricular ischaemic pattern. Records $A$ to $D$ in the figure are consecutive but not continuous. Analysis of these records reveals that long RR cycles favour normal intraventricular conduction while short cycles end with aberrant beats. There is a significant overlap of the critical RR cycles for both types of conduction between 77 and $92^{1}$ (heart rate of $65-78$ beats a minute). However, slowing of the heart rate below the critical level induced by carotid sinus compression (record D) consistently resulted in normal intraventricular conduction, while at higher

1 All intervals are expressed in hundredths of a second. rates induced by amyl nitrite inhalation (record $\mathrm{E})$, exercise, or atropine injection, left intraventricular aberrant conduction, was always observed. The effect of intramuscular injection of $100 \mathrm{mg}$ adenosine triphosphate on the intraventricular conduction was repeatedly studied and was found to lead to normal intraventricular conduction, but this was always associated with slowing of the heart rate below the critical level. The patient was followed for the next two years and intermittent left bundle-branch block could always be seen but the critical rate varied from 52 to 82 beats a minute in several occasions. There was, however, no specific pattern for the change in the critical rate (in particular, no progressive decrease of the critical rate was observed).

Comment This is a simple case of tachycardiadependent left bundle-branch block of unusually long duration. It is interesting to observe both the significant overlap of the critical $R R$ cycles for both types of conduction in the same record and the wide variation of the critical rate for normal intraventricular conduction in records taken on different occasions.

Case 2 A 55-year-old diabetic woman was admitted to hospital in September 1966 with a 


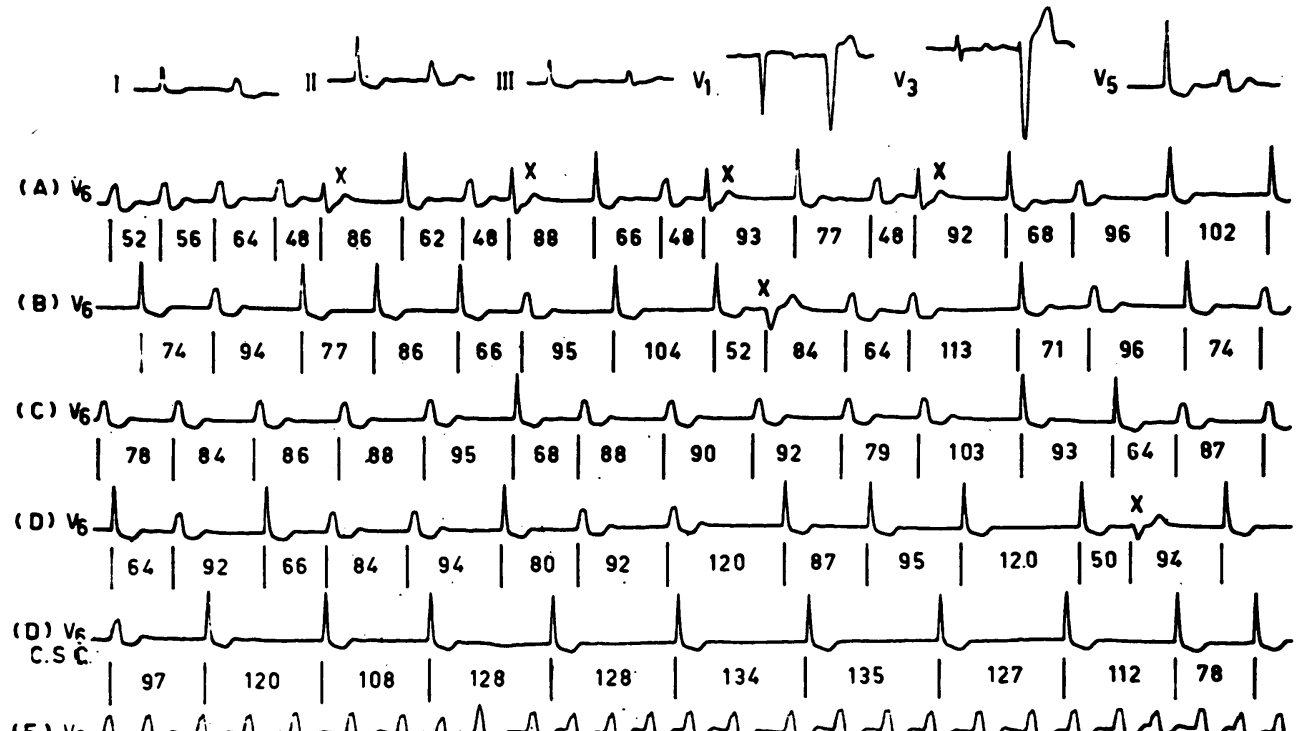

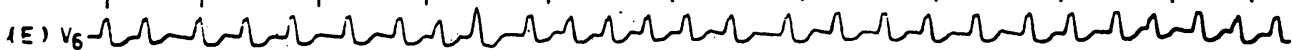

FIG. I Case I, tachycardia-dependent bundle-branch block, record $(D)$ shows the effect of carotid sinus compression (CSC) while record $(E)$ shows the influence of amyl nitrite inhalation. $X$ represents ventricular ectopic systoles.

recent history of recurrent attacks of palpitation. The record in Fig. 2 was obtained at one sitting and was originally divided into two separate sheets that were remounted together with no loss of substance. Lead II shows sinus rhythm at a

FIG. 2 Case 2, tachycardia-dependent left anterior hemiblock.
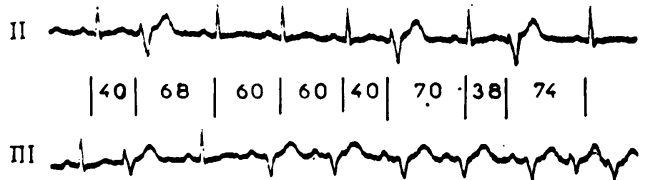

$$
|40| 70|60| 60|57| 56|62| 40|36|
$$

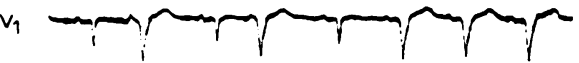$$
|44| 68|40| 72|56| 57|58|
$$$$
\text { ing }
$$$$
58|58| 58|58| 58|58| 58 \mid
$$

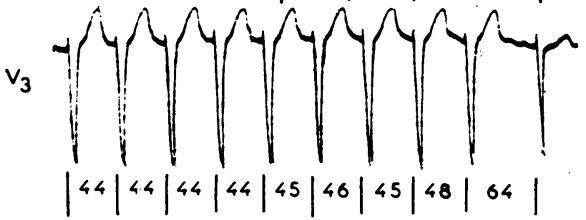

rate of roo beats a minute with normal intraventricular conduction (a QRS pattern with a duration of $0.08 \mathrm{sec}$ ). There are multiple supraventricular ectopic systoles showing aberrant intraventricular conduction (an rS pattern with a duration of $0.1 \mathrm{I}$ sec). This pattern represents a left anterior hemiblock (Rosenbaum et al., 1969). In lead III, the first and third complexes represent normally conducted sinus beats, while the second complex is an aberrantly conducted supraventricular beat. The fourth to eighth complexes are conducted sinus beats at a rate of 97 to 107 beats a minute showing aberrant intraventricular conduction of the same type seen in the ectopic beats (a left anterior hemiblock). The last two beats in lead III start a paroxysm of supraventricular tachycardia and are showing aberrant intraventricular conduction. In lead VI, the first, third, and fifth complexes are normally conducted sinus beats, the second and fourth complexes represent aberrant conduction, as the last three complexes do. Lead V2 shows sinus rhythm at a rate of I03 beats a minute with aberrant intraventricular conduction. Lead $V_{3}$ shows a paroxysm of supraventricular tachycardia at a rate of 136 beats a minute, with aberrant intraventricular conduction. The paroxysm ends before the last beat which reveals normal intraventricular conduction.

Comment This is a simple case of tachycardiadependent left anterior hemiblock. The case shows the close similarity between tachycardiadependent bundle-branch block and intraventricular aberrant conduction of both supraventricular ectopic systoles and tachyarrhythmias. This may help to illustrate the fact that aberrant intra- 
ventricular conduction of either an ectopic supraventricular beat showing a relatively long coupling interval or a supraventricular tachyarrhythmia with only moderate acceleration of the rate may betray an underlying latent bundle-branch block.

Case 6 A 26-year-old man known to have a ventricular septal defect was admitted in February 1969 with the diagnosis of subacute bacterial endocarditis. His cardiogram showed sinus tachycardia (rate I 20 beats a minute), grade I AV block, and a left ventricular ischaemic pattern. The record obtained 3 days later still revealed sinus tachycardia (rate I Io beats a minute) and grade I AV block but showed left bundle-branch block pattern. An attempt was made to uncover normal intraventricular conduction by inducing bradycardia through carotid sinus compression (Fig. 3, records $A$ and $B$ ). Record A shows left bundlebranch block for the first three beats followed by two beats with normal intraventricular conduction, then an escape rhythm occurs at a rate of 75 beats a minute (this represents either an idioventricular tachycardia or an idiojunctional tachycardia with aberrant intraventricular conduction of classical right bundle-branch block pattern). The escape rhythm ends by sinus capture of the ventricle with normal intraventricular conduction that continues for the next four beats before the resumption of aberrant intraventricular conduction in the last two beats. Record B reveals essentially similar findings; however it is interesting to observe that the five beats that represent the escape rhythm in the middle of the record are all fortuitously preceded by sinus $P$ waves at practically constant $P R$ intervals. In records $A$ and $B$, it is seen that normal intraventricular conduction occurs at a critical RR cycle of 57 (heart rate 105 beats a minute). This is best seen during the return of aberrant intraventricular conduction. Records C, D, and E were obtained one week later. The sinus tachycardia had disappeared but the left bundle-branch block was still present at a heart rate of 88 to 90 beats a minute. Normal intraventricular conduction could still be easily induced either by holding the breath after deep inspiration (record C), or carotid sinus compression (record D), or in the pause after an ectopic supraventricular beat (record E). In records $C$ and $D$, normal intraventricular conduction is seen to occur at a critical RR cycle of 68 to 70 (heart rate of $85-88$ beats a minute). In record $\mathrm{D}$, the escape rhythm, which occurs at a relatively slower rate of 68 beats a minute, ends by an early capture of the ventricle after an $R R$ cycle of 6r that results in aberrant intraventricular conduction. The following sinus beats occurring at longer $R R$ cycles reveal normal intraventricular conduction. The patient was successfully treated for the subacute bacterial endocarditis and his records obtained one month later failed to show any evidence of left bundle-branch block at a heart rate of 130 beats a minute induced by amyl nitrite inhalation.

Comment This is a classical case of tachycardiadependent left bundle-branch block. It is interest-

FIG. 3 Case 6, tachycardia-dependent left bundle-branch block. Records $A, B$, and $D$ show the effect of carotid sinus compression (CSC), while record C reveals the influence of deep inspiration, and record $E$ the effect of a supraventricular ectopic systole (marked $X$ ). Note the occurrence of ectopic escape rhythm with right bundle-branch block pattern after carotid sinus compression.

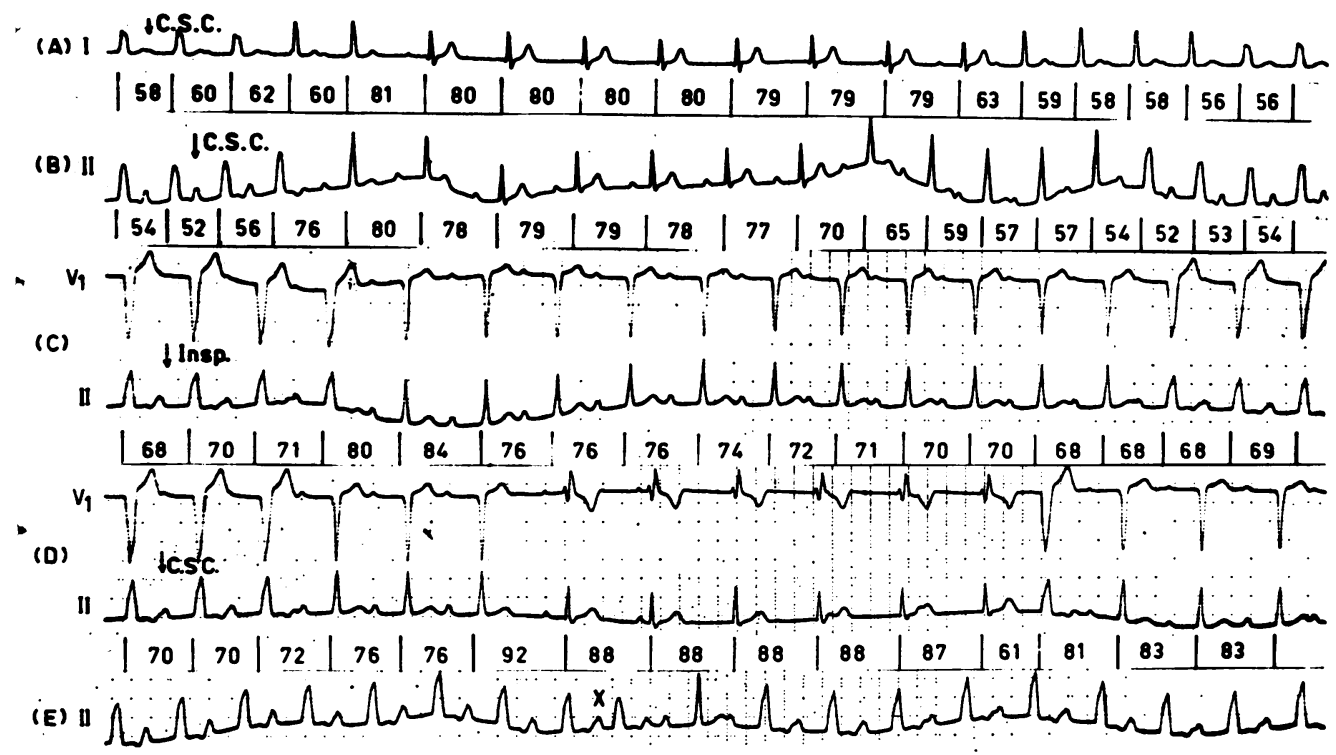



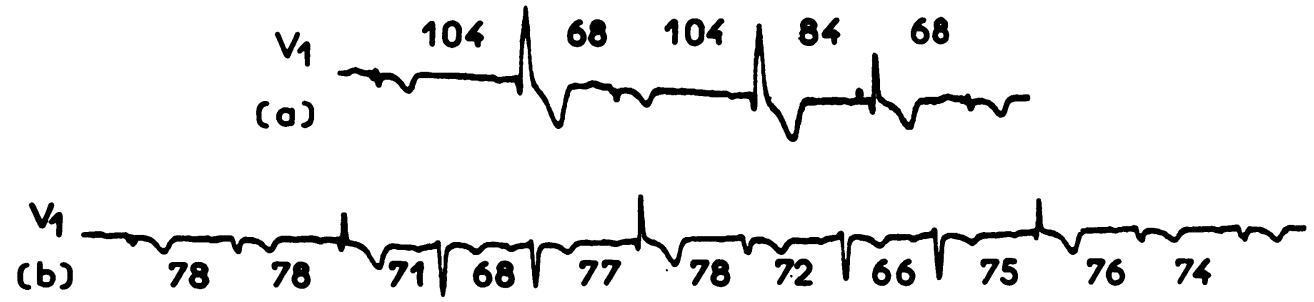

FIG. 4 Case I3, bradycardia-dependent right bundle-branch block.

ing to observe that left bundle-branch block occurred at widely varying heart rates in records taken on different occasions.

\section{Bradycardia-dependent bundle-branch block}

Case 13 A 45-year-old woman with cancer of the body of the uterus was admitted to hospital in September 1966 for a hysterectomy. Her cardiovascular system was clinically free and her preoperative cardiogram was within normal limits. Nine days after operation the patient developed severe dyspnoea with chest oppression and lowering of the blood pressure, and was diagnosed as having a massive pulmonary embolism. The cardiogram taken on the same day showed sinus tachycardia and complete right bundle-branch block. Fig. 4 was recorded three days later and showed intermittent bundle-branch block. The two strips of lead VI show four types of QRS pattern: (a) rS pattern with a duration of $0.08 \mathrm{sec}$ denoting normal intraventricular conduction; (b) rs pattern with notched s wave and a duration of $0.085 \mathrm{sec}$; (c) rsR' pattern with a duration of $0.09 \mathrm{sec}$ (both the second and third patterns represent incomplete right bundle-branch block; (d) $\mathrm{rsR}^{\prime}$ pattern with a duration of $0.13 \mathrm{sec}$ representing complete right bundle-branch block. With the exception of the first, third, and sixth beats in strip VI (a), which are ectopic supraventricular systoles, all complexes are preceded by identical $P$ waves and constant $P R$ intervals and represent conducted sinus beats. Obvious variation in the $R R$ intervals is seen in strip VI (a), while sinus arrhythmia is seen in strip VI (b). It is noted that beats with complete bundle-branch block follow the longest RR intervals, and beats with normal intraventricular conduction follow the shortest intervals, while beats with incomplete bundlebranch block occur at intermediate cycle lengths. A cardiogram taken on the next day revealed normal intraventricular conduction.

Comment This is a classical case of bradycardiadependent right bundle-branch block. The role of the acute but regressive right ventricular overload in the genesis of the intermittent conduction disturbance is remarkable.

Case 14 A 52-year-old man was first seen in March 1965 with a history of myocardial infarction and with evidence of left ventricular failure. His cardiogram showed left bundle-branch block with small $Q$ waves in the left surface leads suggestive of septal infarction. The patient was repeatedly seen later on and his cardiograms always showed bundle-branch block. During a last admission in May 1969, intermittent bundle-branch block was observed for the first time. There were frequent changes from QRS complexes showing complete left bundle-branch block with a duration of 0.17 sec to complexes showing incomplete left bundlebranch block and a duration of 0.11 sec. Fig. 5 shows instances of transition between the two types of intraventricular conduction. Lead I record (A) shows sinus arrhythmia with two beats

FIG. 5 Case I4, lead I in record $(A)$ shows two beats with left bundle-branch block during the slow phase of sinus arrhythmia. Record (B) shows the effect of atropine injection. The observation of both types of intraventricular conduction at widely varying heart rate represents a bradycardia-dependent block. See text for details.

\section{( A )}
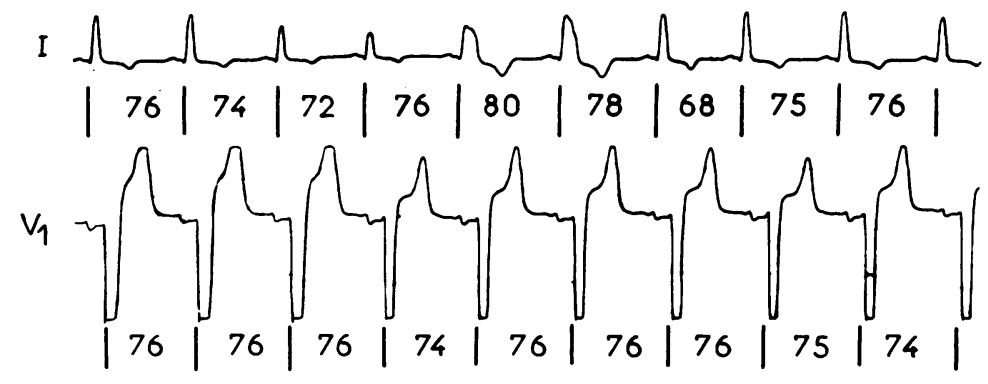

(B)

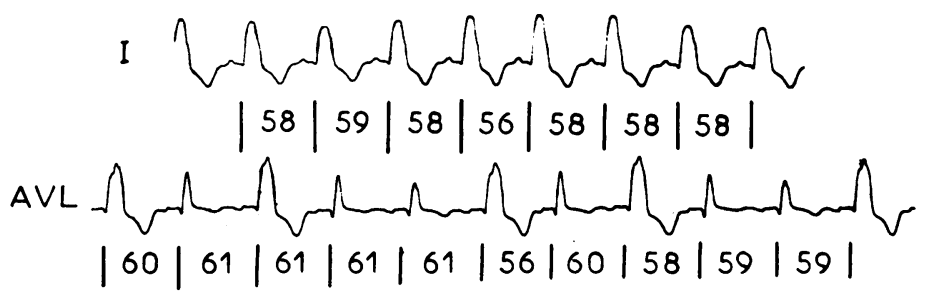


showing complete bundle-branch block occurring during the slow phase of the arrhythmia in the middle of the strip. Lead VI on the other hand shows regular sinus rhythm with the shift from complete to incomplete bundle-branch block unaccompanied by change in the heart rate. Record (B) shows the effect of intravenous injection of $\mathrm{I} \mathrm{mg}$ atropine sulphate administered in the same sitting. Atropine has resulted in sinus tachycardia; still however beats with incomplete bundle-branch block could be observed at $\mathbf{R R}$ intervals of 56-6I (heart rate of 98-107 beats a minute).

Comment There are two interesting observations in the case. Firstly, instances of incomplete left bundle-branch block were only seen for the first time after four years from the first observation of complete block. Secondly, the demonstration of bundle-branch block during the slow phase of sinus arrhythmia and the observation of both types of intraventricular conduction at a widely varying heart rate represent bradycardia-dependent left bundle-branch block.

Case 16 A 55-year-old man was first seen in February 1967 with a history of recent myocardial infarction. His cardiogram showed complete right bundle-branch block with ST-T changes suggestive of recent anterolateral injury pattern. There were frequent ventricular ectopic systoles that usually occurred in pairs. Record (A) in Fig. 6 was obtained shortly after admission. In the record, both the conducted sinus beat (strip (VIa) and the junctional escape beat (strip VIb) which follow the compensatory pause of the second ectopic systole reveal normal intraventricular conduction. The records under (B) were obtained two weeks later. Strip VI shows frequent spontaneous transition from a right bundlebranch block pattern to beats showing a slight degree of incomplete right bundle-branch block $\left(\mathrm{rSr}^{\prime}\right)$. The second to fourth strips show the effect of carotid sinus compression. In strip VI, carotid sinus compression gives rise to a pause followed by a junctional escape beat which still reveals complete bundle-branch block. This is followed by two junctional escape beats with normal intraventricular conduction before the resumption of conducted sinus beats showing slight degree of incomplete right bundle-branch block. Lead aVR shows nearly similar findings. In lead I on the other hand, immediately after carotid sinus compression there is a sinus beat with slight aberrant conduction followed by three junctional escape beats all showing complete bundle-branch block before the resumption of conducted sinus beats with slight aberration at the end of the strip.

Comment The observation under record (A) where the compensatory pause after ventricular ectopic systoles allows for functional recovery of the diseased bundle, represents a tachycardiadependent bundle-branch block. On the other hand, the findings in record (B) obtained two weeks later, are more interesting: the persistence of bundle-branch block in the beat immediately after carotid sinus compression though preceded by an RR interval which is longer than the intervals during the following sinus beats with normal

FIG. 6 Case 16, record $(A)$ shows multiple ventricular ectopic systoles revealing a tachycardia-dependent right bundle-branch block during an acute myocardial infarction. Record (B) obtained two weeks later shows the effect of carotid sinus compression (CSC) which reveals a bradycardia-dependent bundle-branch block. See text for details.

( A )

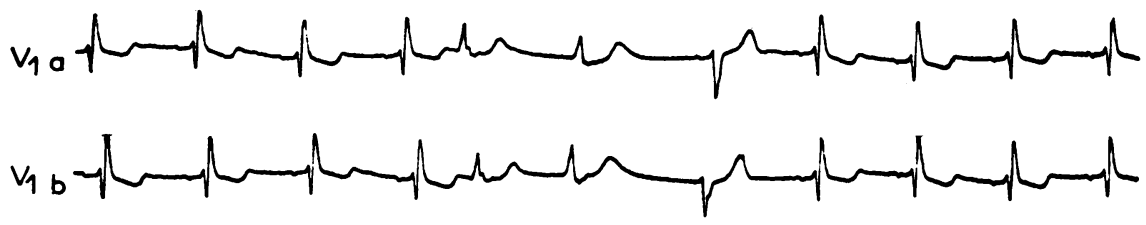

( B )
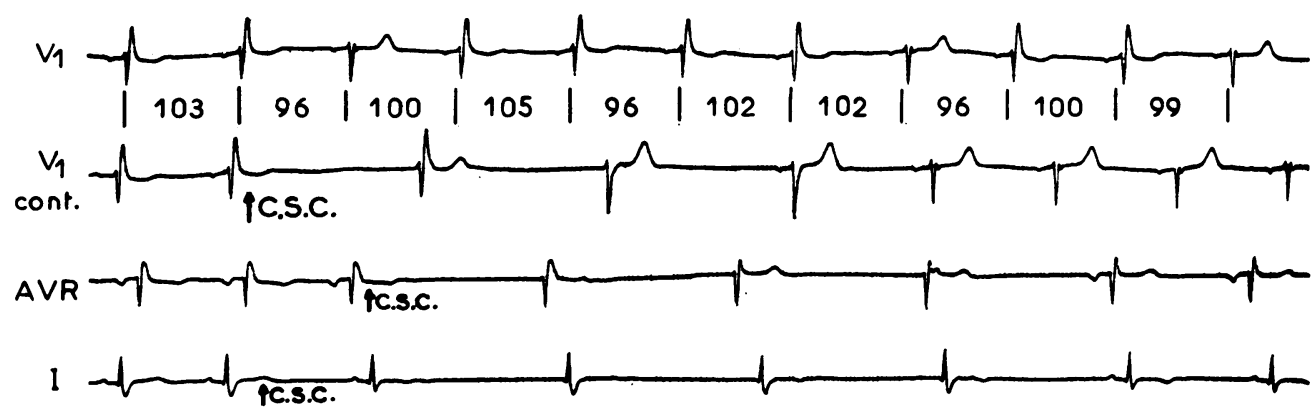
intraventricular conduction, and the demonstration of a slow junctional rhythm with bundlebranch block, represent a bradycardia-dependent bundle-branch block. It is interesting to show the operation of two different mechanisms of intermittent bundle-branch block in the same case on two different occasions.

\section{Discussion}

The occurrence of bundle-branch block when a critical heart rate is exceeded is in accordance with known electrophysiological characteristics of the conduction system. Thus an impulse arriving to the bundle-branches at an $R R$ interval shorter than its effective refractory period will be either delayed or blocked. This is readily explained in terms of impulse spread through incompletely repolarized fibres. However, bundle-branch block developing at very short RR intervals (whether these are observed to occur once as in the case of an early coupled supraventricular ectopic systole or repetitively as in the case of a supraventricular tachyarrhythmia) will be explained by the time necessary for the physiochemical processes of recovery (Burch, 1962) and will not be considered pathological. The refractory periods of the specialized conducting system are known to shorten with abbreviation of the preceding cycle length (Hoffman and Cranefield, I960; Linhart, Braunwald, and Ross, 1965; Moe, Mendez, and Han, 1965). Usually during tachycardia, the functional refractory period of the bundle-branch system shortens relatively more than that of the AV junctional tissue and bundle of His, permitting after a few beats the passage through that bundlebranch system again (Moe et al., 1965). In certain instances, however, the impulse conduction may be interfered with (delayed or blocked) at the AV junctional-bundle of His level before reaching the bundle-branch system, which simply means a longer effective refractory period at the former regions. This will help us to remember that disturbances of conduction at the $\mathrm{AV}$ junctional-bundle of His level may completely mask significant disease at the bundle-branch system. On the other hand, bundle-branch block observed to occur at relatively long RR intervals is pathological and denotes abnormal prolongation of the effective refractory period of the bundlebranch system.

The demonstration of a cycle lengthrecovery time relation stimulated various authors to formulate the concept of critical heart rate in intermittent bundle-branch block. Some even suggested that the change from intermittent to permanent bundlebranch block might be effected through a constantly decreasing critical heart rate until such a time as the block was no longer reversible (Shearn and Rytand, 1953). Much evidence however argues against incrimination of the heart rate as the sole determinant responsible for intermittent bundle-branch block. Thus, though in some records of intermittent bundle-branch block a critical RR cycle could be seen that varied for no more than a few hundredths of a second, yet in other records more overlap could usually be seen. On the other hand, bundle-branch block at widely varying heart rates may be observed in records taken on different occasions or in the same record under the influence of a variety of physiological manoeuvres and pharmacological agents. These and similar observations entailed the search of other factors besides a critical rate that may influence impulse conduction in the bundle-branch system. Out of these factors, the effect of vagal impulses and momentary changes in coronary perfusion received much attention. Vagal impulses were thought to act on the conduction at the bundle-branch system in a similar fashion to its established role on conduction at the AV junctional tissue. Vesell and Lowen (1963) had critically discussed the subject; however, controversy prevails not only in relation to clinical observations (Wilson, 1915; Holzmann, I943; Katz and Pick, 1956; Scherf, Blumenfeld, and Yildiz, I96I) but even in experimental and anatomical studies (Mitchell, Brown, and Cookson, 1953; Cranefield, Hoffman, and Paes de Carvalho, 1959; Eliakim et al., 196I ; Truex, 196I). The effect of momentary changes in coronary perfusion is even more controversial. Reduced blood supply to the bundle-branch system was thought to act through local metabolic and physico-chemical changes altering the transmembrane ionic gradient, with secondary prolongation of the refractory period (Vesell and Lowen, 1963).

The presence of slight overlap of the RR cycles of normal and aberrant beats in records showing tachycardia-dependent bundlebranch block does not argue against the presence of a cycle length-recovery time relation. This observation, which is more commonly seen in the presence of atrial fibrillation (Fig. I), may reflect, in fact, the sensitivity of the action potential duration of the diseased bundle to the possible cumulative effects of cycle length changes. Alteration in cycle length results in altered cell action potential. It has been found that when the heart rate suddenly changes, it may take several beats before a constant action potential is achieved for that rate (Hoffman and Cranefield, 1960). 
In contrast to the slight overlap of the critical $R R$ cycle in the same record, the demonstration of bundle-branch block at widely varying heart rates in records taken on different occasions probably reflects the influence of slowly acting parameters, such as progressive or regressive ischaemic changes, that may alter the action potential duration of the diseased bundle-branch system.

On the other hand, it is interesting to observe that most of the reports that invoked vagal influence or momentary changes in coronary perfusion especially when certain physiological manoeuvres or pharmacological agents were applied, had shown either bundlebranch block occurring at relative slowing of the heart rate or alternatively normal intraventricular conduction at relative acceleration of the rate. This situation, termed bradycardiadependent bundle-branch block (signifying 'slower' rather than 'slow' heart rate), finds a more ready explanation through the concept of enhanced phase-4 depolarization. It is obvious that in the interpretation of records showing bradycardia-dependent bundlebranch block, the abnormality cannot be explained on the basis of impulse spread through incompletely repolarized fibres as in the case of tachycardia-dependent bundlebranch block. It has been shown however that a 'slower' ventricular rate may facilitate phase- 4 depolarization of automatic cells. Sufficient reduction of the diastolic membrane potential will cause reduction in amplitude and $\mathrm{dv} / \mathrm{dt}$ of action potentials initiated in automatic cells and alteration in conduction, ranging from simple slowing to decrimental unidirectional and bidirectional block (Singer, Lazzara, and Hoffman, 1967). The abnormalities are comparable to those that occur if the impulse is conducted during repolarization at corresponding level of membrane potential (Kao and Hoffman, I958; Van Dam, Moore, and Hoffman, 1963). Agents and means that enhance or suppress phase- 4 depolarization in the human heart can consequently induce or improve conduction abnormalities caused by this mechanism (Singer et $a l .$, 1967). Thus, some of the physiological manoeuvres and pharmacological agents that were suggested to act through their influence on a presumed vagal control on the bundlebranch system or through momentary changes in coronary perfusion can be more reasonably explained through their effect on phase-4 depolarization. On these grounds, the bundlebranch block appearing after carotid sinus compression in Case I6 (Fig. 6) can be explained by vagal-induced AV slowing with junctional escape rhythm which permitted the exposure of occult diastolic depolarization, the latter leading to impaired conduction in the corresponding bundle-branch. The occurrence of enhanced phase- 4 depolarization and bradycardia-dependent bundlebranch block in the case two weeks after records showing tachycardia-dependent block may be related to variations in the blood supply of the diseased bundle. On the other hand, atropine used in Case 14 had probably 'overdriven' the slow diastolic depolarization present and in consequence bundle-branch block appearing at a slow rate was replaced by a narrow $Q R S$ complex when the rate was speeded by this drug.

In spite of the previous considerations, bradycardia-dependent bundle-branch block is still the subject of a good deal of misconception. This has been recently outlined by Massumi (1968) who has only accepted 4 cases from the earlier published reports (Dressler, I959; Wallace and Lazlo, I96I; Bauer, Julian, and Valentine, 1956) to which he added another 4 cases of his own. However, 3 of his cases (Cases 2 to 4 ) represented equivocal examples. It is interesting to observe that in his second case the diagnosis of bradycardia-dependent block was made on the assumption that the occurrence of six consecutive escape beats, fortuitously preceded by $P$ waves, was highly improbable; in addition, the QRS configuration was that of typical right bundle-branch block. Both situations are however illustrated in Fig. 3 record (B) in the presence of an unequivocal escape rhythm. This stresses the value of the analysis of long strips for correct interpretation of cardiac arrhythmias. As a matter of fact, if the escape rhythm in our case and in the second case of Massumi were of junctional origin, the aberrant intraventricular conduction will represent a form of bradycardia-dependent bundle-branch block involving the right bundle-branch system. The aberration of junctional escape beats can be generally explained on the same lines as bradycardiadependent block (Sarachek, I970). In our case, the left bundle will also reveal a tachycardia-dependent block.

\section{References}

Bauer, G. E. (1964). Transient bundle-branch block. Circulation, 29, 730.

Bauer, G. E., Julian, D. G., and Valentine, P. A. (I965). Bundle-branch block in acute myocardial infarction. British Heart fournal, 27, 724.

Burch, G. E. (1962). Relationship of heart rate to cardiac output, work, power, and tension in man. fournal of the American Medical Association, 182, 339. 
Cranefield, P. F., Hoffman, B. F., and Paes de Carvalho, A. (1959). Effects of acetylcholine on single fibers of the atrioventricular node. Circulation Research, 7, 19.

Dressler, W. (1959). Transient bundle-branch block occurring during slowing of the heart beat and following gagging. American Heart fournal, 58, 760.

Eliakim, M., Bellet, S., Tawil, E., and Muller, O. F. (196I). Effects of vagal stimulation and acetylcholine on the ventricle: studies in dogs with complete A-V block. 34th Scientific Session, American Heart Association (Abstract). Circulation, 24, 925.

Hoffman, B., and Cranefield, P. (1960). Electrophysiology of the Heart, pp. I80 and 275. McGraw Hill, New York.

Holzmann, M. (1943). Seltene Abarten von unbeständigem Schenkelblock. Cardiologia, 7, I 13.

Kao, C. Y., and Hoffman, B. F. (1958). Graded and decremental response in heart muscle fibers. American fournal of Physiology, 194, 187.

Katz, L. N., and Pick, A. (1956). Clinical Electrocardiography. Part I. The Arrhythmias, p. 467. Lea and Febiger, Philadelphia; Kimpton, London.

Linhart, J. W., Braunwald, E., and Ross, J. (1965). Determinants of the duration of the refractory period of the atrioventricular nodal system in man. fournal of Clinical Investigation, 44, 883.

Massumi, R. A. (I968). Bradycardia-dependent bundle-branch block. A critique and proposed criteria. Circulation, 38, 1066.

Mitchell, G. A. G., Brown, R., and Cookson, F. B. (1953). Ventricular nerve cells in mammals. Nature (London), 172, 812 .

Moe, G. K., Mendez, C., and Han, J. (1965). Aberrant A-V impulse propagation in the dog heart: A study of functional bundle-branch block. Circulation Research, 16, 26I.

Rosenbaum, M. B., Elizari, M. V., Levi, R. J., Nau, G. J., Pisani, N., Lazzari, J. O., and Halpern, M. S. (1969). Five cases of intermittent left anterior hemiblock. American fournal of Cardiology, 24, r.
Sarachek, N. S. (1970). Bradycardia-dependent bundle-branch block. Relation to supernormal conduction and phase- 4 depolarization. American fournal of Cardiology, 25, 727.

Scherf, D., Blumenfeld, S., and Yildiz, M. (I96I). Experimental study on ventricular extrasystoles provoked by vagal stimulation. American Heart fournal, 62, 670 .

Shearn, M. A., and Rytand, D. A. (1953). Intermittent bundle-branch block. Observations with special reference to the critical heart rate. Archives of Internal Medicine, 91, 448.

Singer, D. H., Lazzara, R., and Hoffman, B. F. (1967). Inter-relationships between automaticity and conduction in Purkinje fibres. Circulation Research, 21, 537.

Truex, R. C. (196I). Comparative anatomy and functional considerations of the cardiac conduction system. In Symposium on the Specialized Tissues of the Heart, pp. 22 and 36. Ed. by A. P. de Carvalho, W. C. de Mello, and B. F. Hoffman. Elsevier Publishing Company, New York.

Van Dam, R. T., Moore, E. N., and Hoffman, B. F. (1963). Initiation and conduction of impulses in partially depolarized cardiac fibers. American fournal of Physiology, 204, I 133.

Vesell, H., and Lowen, G. (1963). Bundle-branch block on cardiac slowing at a critical slow heart rate. American Heart fournal, 66, 329.

Wallace, A. G., and Lazlo, J. (196r). Mechanisms influencing conduction in a case of intermittent bundle-branch block. American Heart fournal, 6r, 548.

Wilson, F. N. (1915). A case in which the vagus influenced the form of the ventricular complex of the electrocardiogram. Archives of Internal Medicine, 16, 1008.

Requests for reprints to Dr. Nabil El-Sherif, Cardiology Department, Faculty of Medicine, Cairo University, Cairo, Egypt, U.A.R. 